\title{
Contribuições do Superlogo ao ensino de geometria
}

\author{
Contributions of Superlogo software \\ to geometry teaching methodology
}

\begin{abstract}
Resumo:
Existem inúmeras críticas ao ensino de Geometria. Alguns pesquisadores afirmam que o trabalho docente, no qual predomina a memorização em detrimento à compreensão, não incentiva o aluno a buscar uma aprendizagem significativa, podendo despertar atitudes negativas em relação à aquisição de conceitos. O ideal seria trabalhar em um ambiente em que a geometria pudesse ser desenvolvida de forma concreta e lúdica, motivando a criatividade e o raciocínio lógico-matemático. Nessa direção, o ambiente proporcionado pelo SuperLogo exerce um papel fundamental ao auxiliar o processo de ensino/aprendizagem e o raciocínio criativo, abrindo perspectivas de trabalho, valorizando a resolução de problemas e tornando as idéias matemáticas significativas. Assim, este artigo tem por objetivo discutir sobre a importância da utilização do Programa Computacional SuperLogo, analisando suas principais contribuições ao ensino e desenvolvendo nos alunos uma aprendizagem significativa dos conceitos geométricos, fazendo com que o educando pense a respeito de si próprio, tornando-se agente ativo na construção de sua própria aprendizagem, favorecendo o processo de desenvolvimento cognitivo.

Palavras-chaves: Matemática. Informática. Geometria. Tecnologia. SuperLogo.
\end{abstract}

\section{Abstract:}

At present, there is still a lot of criticism in relation to $\mathrm{Ge}$ ometry teaching methods. Some researchers claim that, in the current teaching methodology the technique which predominates is marked by memorization instead of real understanding. As a result, the memorization of these concepts can lead students to negative attitudes towards the acquisition of geometrical notions. The ideal situation would be choosing teaching procedures in which these concepts could be developed in a pleasant and concrete mood, hence it would motivate students' thinking and consequently help them during their learning process. thus, this commentary has the aim to discuss about the relevance of Superlogo Software usage. Analyzing its main contributions for teaching ideas and the manner it raises meaningful knowledge related to geometrical conceptions to the students. Key-words: Mathematics. Information. Geometry. Technology. Superlogo.

MOTTA, M. S, SILVEIRA, I. F. Contribuições do Superlogo ao ensino de geometria. Informática na Educação: teoria \& prática, Porto Alegre, v. 13, n. 1, p. 115-127, jan./jun. 2010.

\author{
Marcelo Souza Motta \\ Ismar Frango Silveira \\ Universidade Federal do Mato Grosso do Sul \\ Universidade Cruzeiro do Sul
}

\section{Introdução}

A nalisando as atuais reformulações e adaptações curriculares do ensino de Matemática, pode-se afirmar que a educação atravessa um período de profundas mudanças, à medida que deseja conciliar seus objetivos ao interesse e realidade social.

Essa visão contrasta-se com aquela presente em algumas escolas, segundo a qual a matemática é vista como um corpo de conhecimento imutável e verdadeiro, que deve ser simplesmente assimilado pelo aluno, dentro de uma concepção tradicionalista de ensino.

Ao definir os objetivos do ensino de matemática para a Educação Básica, os Parâmetros Curriculares Nacionais (PCN's) destacam que o aluno deve "[...] valorizá-la como instrumental para compreender o seu dia-a-dia, vendo-a como área que estimula o interesse, curiosidade, investigação e o raciocínio lógico." (BRASIL, 2001, p. 15)

Nessa forma de pensar a aprendizagem matemática, o aluno deve aprender a utilizar os procedimentos matemáticos, os instrumentos tecnológicos disponíveis, comunicar-se com idéias matemáticas significativas e argumentar sobre suas conjecturas. 
$\mathrm{Na}$ perspectiva de desenvolvimento do pensamento matemático e dos processos cognitivos internos, destaca-se a Geometria. Os PCN's apontam que o ensino de geometria "[...] é um campo fértil de situações-problema que favorece o desenvolvimento da capacidade para argumentar e construir demonstrações." (BRASIL, 2001, p. 122)

Existem diversas metodologias que podem ser utilizadas para o desenvolvimento dos conceitos geométricos, dentre elas destaca-se a utilização das tecnologias da informação. A informática está a serviço do ensino e aprendizagem da matemática, pois proporciona ao aluno a criação de uma imagem diferente da disciplina, bem como o enriquecimento de práticas pedagógicas que desenvolvem a exploração, a criatividade, a ludicidade, o raciocínio lógico, a interatividade, a socialização, a afetividade e a reflexão crítica.

Nesse contexto, e examinando os vários ambientes de aprendizagem virtual existentes (Cabri Geométre, DrGeo, SuperLogo, Cinderella e The Geometer's Sketchpad) que proporcionam a construção de conceitos geométricos, optou-se neste trabalho pelo Programa Computacional SuperLogo. O software propicia a construção de uma aprendizagem significativa, facilita o saber e contribui para a constituição das estruturas mentais. Com o SuperLogo os alunos têm a oportunidade de acertar ou errar e, quando erram, podem investigar o motivo do erro, tendo a oportunidade de fazer e refazer suas atividades.

Com o conhecimento das vantagens pedagógicas e das potencialidades do programa, cria-se um ambiente de trabalho favorável à superação de lacunas que os alunos têm na assimilação de conceitos geométricos, ou seja, ocorre uma ressignificação desses conteúdos. Assim "[...] ao trabalhar com o SuperLogo, os alunos demonstram em geral o comportamento de envolvimento nas tarefas, de apreciação da atividade matemática subjacente, e o gosto pelo domínio de computadores." (MATOS, 1991)

Portanto, o presente artigo objetiva verificar de que forma o SuperLogo contribui para o aprimoramento de conceitos geométricos dos alunos no sétimo ano da Educação Básica.

\section{Ambientes informatizados de aprendizagem matemática}

Os Ambientes Informatizados de Aprendizagem (AIA) são programas desenvolvidos para atender a objetivos educacionais específicos. Segundo Costa e Oliveira (2004), esses ambientes podem ser conceituados como espaços de relação com o saber, que favorecem a construção do conhecimento, permitindo a aprendizagem de conteúdos, habilidades e atitudes.

Os Ambientes de Aprendizagem propiciam a integração de várias disciplinas que compõem a grade curricular dos alunos, visto que promovem articulações entre os diversos campos do saber, o que cria autonomia necessária para que o aluno desenvolva sua tecnologia mental de forma a auxiliá-lo no seu dia a dia e nas interações com os objetos do conhecimento.

Para Costa e Oliveira:

O uso das NTs na escola caracteriza o que chamamos de Ambiente Informatizado de Aprendizagem (AIA). Isto só se configura quando se integra criticamente à tecnologia de informática o processo educativo, onde o computador como recurso pedagógico não goza de autonomia para a condução do processo ensino-aprendizagem. (COSTA; OLIVEIRA, 2004, p. 27)

Os autores sugerem que os computadores estejam presentes na escola como uma tecnologia intelectual a favor da aprendizagem desenvolvida pelos alunos. Essa interação amplia as relações entre sujeito e o objeto, criando um modelo virtual de realidade.

A utilização dos Ambientes Informatizados de Aprendizagem está incorporando à aprendizagem uma série de situações positivas que são: a independência no intercâmbio com o software; a busca por padrões em um problema; a interação entre os alunos; a criatividade; o diálogo de uma linguagem específica; a relação com outros idiomas; a visão do computador como fonte de aprendizado e o desenvolvimento de processos cognitivos.

O trabalho com ambientes informatizados motiva o aluno a vários tipos de aprendizagem, como afirmam Costa e Oliveira:

O aluno no contato com os objetos de aprendizagem utiliza seus esquemas de pensamento 
para a construção de novos saberes que passarão progressivamente a compor sua bagagem de conhecimentos, numa recursividade perene de ações e interações com o meio do conhecimento. (COSTA; OLIVEIRA, 2004, p. 27)

Esses ambientes merecem destaque no desenvolvimento de conceitos matemáticos. Segundo os PCN's (2001), o uso desses recursos traz significativas contribuições para se repensar o processo ensino-aprendizagem de Matemática à medida que:

Relativiza a importância do cálculo mecânico e da simples manipulação simbólica; evidencia para os alunos a importância do papel da linguagem gráfica e de novas formas de representação, permitindo novas estratégias de abordagem de variados problemas; possibilita o desenvolvimento, nos alunos, de um crescente interesse pela realização de projetos e atividades de investigação e exploração; permite que os alunos construam uma visão mais completa da verdadeira natureza da atividade matemática e desenvolvam atitudes positivas diante de seu estudo. (BRASIL, 2001, p. 44)

A utilização do computador só contribui para que o processo de ensino e aprendizagem de matemática torne-se uma atividade experimental e rica, caso o aluno seja instigado a desenvolver processos matemáticos fundamentais que caracterizam o fazer matemático, tais como: experimentar, interpretar, visualizar, induzir, conjecturar, abstrair, generalizar e demonstrar.

Nessa atual sociedade do conhecimento, onde o científico está vinculado ao raciocínio causal, organizado, sistêmico e lógico, a Matemática acontece como requisito conceitual científico. Se fazer ciência é matematizar os fenômenos, realizando sua leitura e compreensão pelo raciocínio lógicodedutivo, essência da estruturação Matemática, a educação tecnológica ou para tecnologia se faz numa interação estreita com a Educação Matemática. (LAUDARES, 2004, p. 297)

Nesse contexto, a Matemática está amplamente relacionada com as tecnologias da informação. Segundo Miranda e Laudares:

A matemática é o sustentáculo lógico do processamento da informação, e o pensamento matemático é também a base para as atuais aplicações da tecnologia da informação. De fato, todas as aplicações de um computador podem ser vistas como uma aplicação de um modelo matemático simples ou complexo. (MIRANDA; LAUDARES, 2007, p. 03)
Nesses ambientes de aprendizagem, o professor desempenha um papel fundamental na elaboração de estratégias centradas na experimentação que proporcionam ao aluno um ambiente de trabalho que amplia seu próprio conhecimento.

Portanto, os ambientes informatizados apresentam-se como ferramentas de grande potencial frente aos obstáculos inerentes ao processo da aprendizagem matemática, pois oferecem recursos que viabilizam as ações mentais, favorecendo um modelo pedagógico construtivista.

O Ambiente Informatizado de Aprendizagem destacado neste artigo é o SuperLogo, pois apresenta as potencialidades educativas necessárias ao processo cognitivo da matemática e uma grande facilidade de interação por parte dos alunos.

Ponte e Canavarro (1997) afirmam que a Linguagem Logo é um excelente ambiente de aprendizagem matemática, pois a geometria desenvolvida no software constitui um ambiente estimulante, que incentiva os alunos a desenvolver procedimentos para ensinar a tartaruga na construção de figuras simples ou complexas.

Assim, o SuperLogo desenvolve um ambiente facilitador, no qual o aluno é o sujeito ativo no processo ensino-aprendizagem através da mediação do professor. Esse intercâmbio ocorrerá por meio de interações com a linguagem de programação, desenvolvendo ou dando novo significado aos conhecimentos geométricos.

\section{Conhecendo o SuperLogo}

A linguagem LOGO foi desenvolvida nos EUA, no Massachusetts Institute of Tecnology (MIT), na década de 60, a partir de pesquisas feitas pelos matemáticos Seymour Papert e Wallace Feurzeig, diretor da MIT. Conta-se que a idéia surgiu durante um jantar em que estava proposta a criação de uma linguagem de programação para substituir o Basic. Daí nasceu o Logo, uma linguagem com a capacidade de processar listas e de permitir a criação de procedimentos.

Nessa época, o Logo não possuía uma interface gráfica, pois os computadores não tinham essa habilidade, tornando-se impossível 
sua implementação. Assim, no meio de sua pesquisa, Papert deu ao Logo uma visão filosófica baseada na teoria piagetiana, que propõe um aprendizado calcado nas diferenças individuais, na reflexão sobre o próprio processo de aprendizagem e na lógica do pensamento.

Para Papert (1985), a aquisição de um conhecimento não se dá em função do desenvolvimento físico, mas principalmente através da forma de relacionamento das pessoas com o meio.

De acordo com o princípio construcionista de Papert, o objetivo principal do SuperLogo é tornar o aluno agente ativo de sua aprendizagem. Correia (2001) destaca que as principais características do software são: Amigabilidade pois, é de fácil uso e facilmente assimilado pelo aluno. Modularidade e Extensibilidade permitindo ao aluno incluir ou excluir comandos. Interatividade permite que o aluno veja e pense sobre seu erro imediatamente após a execução dos comandos. Flexibilidade O SuperLogo pode ser utilizados em todos os níveis de estudo (Fundamental, Médio e Superior). Capacidade pois, permite ao aluno desenvolver uma linguagem de programação específica do software desenvolvendo o raciocínio e a lógica.

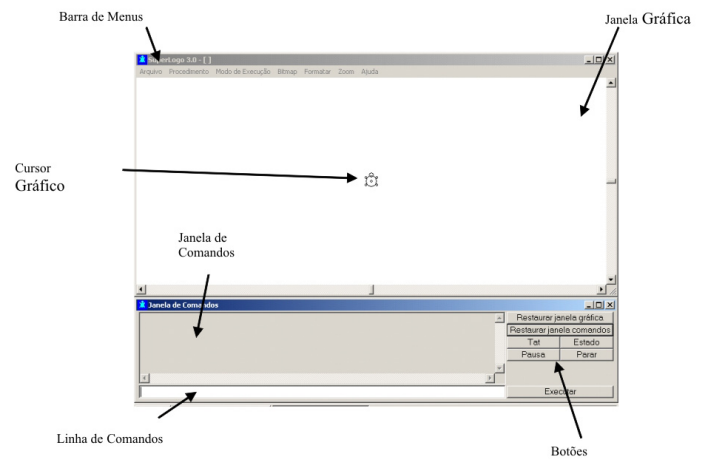

FIGURA 1 - Tela Inicial do SuperLogo

Existem inúmeras versões da Linguagem SuperLogo. Nesta investigação, utilizou-se somente a versão do SuperLogo 3.0, que é a linguagem de programação original adaptada para o português pelo Núcleo de Informática Educativa à Educação (NIED) da Universidade de Campinas. A escolha pela versão produzida pelo NIED levou em consideração o fato do programa ser traduzido para o português, e de ser um software gratuito e disponível para download.
Ao iniciar o programa aparecerão duas janelas: a Janela Gráfica e a Janela de Comandos. Juntas formam o ambiente do SuperLogo (ver Figura 1).

Os comandos básicos para movimentação da tartaruga são idênticos a quando se realiza uma caminhada, ou seja, anda-se para frente, para trás, para a direita ou para esquerda. A diferença é que, usando um recurso computacional, deve-se indicar qual o deslocamento e o giro. No SuperLogo consideramos a equivalência de que para cada $1 \mathrm{~cm}$ temos 50 passos de tartaruga, ou seja, 50 pixels.

Os comandos básicos de movimentação da tartaruga são apresentados na Tabela 1.

TABELA 1 - Comandos Básicos do SuperLogo

\begin{tabular}{c|c|c}
\hline Comando & Mnemônico & Função \\
\hline parafrente & pf & $\begin{array}{c}\text { Descolamento para } \\
\text { frente }\end{array}$ \\
\hline paratras & pt & Descolamento para trás \\
\hline paraesquerda & pe & $\begin{array}{c}\text { Gira para a esquerda de } \\
\text { acordo com seu eixo de } \\
\text { simetria em um ângulo } \\
\text { específico }\end{array}$ \\
\hline paradireita & pd & $\begin{array}{c}\text { Gira para a direita de } \\
\text { acordo com seu eixo de } \\
\text { simetria em um ângulo } \\
\text { específico }\end{array}$ \\
\hline
\end{tabular}

Existem diversos outros comandos no SuperLogo, além dos apresentados na tabela acima, tais como: desabilitar a tartaruga a traçar na tela, permitir apagar segmentos, habilitar o lápis, trazer a tartaruga para o centro, desenhar em três dimensões, escrever na tela, efetuar operações aritméticas e lógicas, traçar círculos e arcos, colorir desenhos, etc.

Uma de suas principais ferramentas é o desenvolvimento de projetos utilizando uma linguagem de programação específica do software o qual denomina-se procedimento. Procedimento é um conjunto de instruções ensinadas ao SuperLogo que recebe um nome e se propõe a executar determinada ação. Por exemplo, pode-se ensinar um procedimento chamado quadrado, em que toda vez que é preciso desenhar um quadrado, basta executar o procedimento ensinado.

Todas essas funcionalidades podem ser mais bem descritas e observadas na dissertação de mestrado Contribuições do SuperLogo ao Ensino de Geometria do Sétimo Ano 
da Educação Básica, desenvolvida pelo autor deste artigo e disponível na Biblioteca Central da Pontifícia Universidade Católica de Minas Gerais (PUCMINAS) 1 .

\section{Metodologia da pesquisa}

Esta pesquisa teve como proposta, investigar e analisar as interações dos alunos com o programa e o professor, através da observação de seus desenvolvimentos cognitivos numa perspectiva piagetiana; e os processos computacionais envolvidos na construção da aprendizagem na visão de Papert.

A metodologia tem como característica a utilização de uma pesquisa participante, possuindo grande envolvimento do pesquisador como sujeito ativo e presente durante toda a observação.

Para Ludke e André (1986), a pesquisa participante surgiu para responder às questões propostas pelos atuais desafios da pesquisa educacional os quais surgiram da curiosidade investigativa despertada por problemas revelados na educação e também foram fortemente influenciados por uma nova atitude de pesquisa, que coloca o pesquisador no meio da cena investigada.

A abordagem metodológica utilizada no trabalho enquadra-se em um modelo de pesquisa qualitativa, pois não tem como objetivo quantificar somente os resultados, mas, tenta detectar e analisar possíveis impactos da utilização do SuperLogo nos conhecimentos geométricos dos alunos.

Cabe ressaltar que, embora os principais procedimentos de pesquisa adotados por este trabalho possuam um caráter qualitativo, fazse necessário utilizar, em alguns momentos, dados quantitativos para justificar inferências e conclusões estabelecidas.

Fizeram parte deste estudo 20 alunos do sétimo ano da Educação Básica. O desenvolvimento da pesquisa ocorreu em dupla, durante quatro meses, num total de vinte aulas com duração aproximada de cinqüenta minutos cada. As primeiras doze aulas destinaram-se a familiarização dos alunos com o ambiente e as oito

1 Disponível também para download no site: http://www. pucminas.br/biblioteca. aulas restantes foram utilizadas para o desenvolvimento das atividades investigativas.

Durante a realização das atividades, os alunos tiveram contato com vários conceitos geométricos essenciais a matemática: Figuras geométricas, ângulos, polígonos, coordenadas cartesianas, medidas, perímetro, área, volume e fórmulas.

Cinco docentes da instituição também foram foco de análises. São professores de matemática que atendem do ensino básico ao médio. Por meio de questionários e entrevistas, várias questões foram levantadas, dentre elas destacam-se a formação do professor, a participação em atividades realizadas no laboratório de informática e o conhecimento do programa SuperLogo.

O quadro em que se desenvolveu a pesquisa fortalece a idéia de que o professor deve ser o mediador no desenvolvimento cognitivo dos alunos e na interação em ambientes informatizados de aprendizagem. Laudares e Miranda no artigo Informatização no Ensino da Matemática: investindo no ambiente de aprendizagem, afirmam que:

[...] o professor é impelido a converter-se em mediador, a mostrar aos alunos os caminhos para atingir a autonomia em relação ao conhecimento. Assim, ambiente e professor integrados são constituintes de um espaço escolar adequado ao desenvolvimento da didática, na perspectiva de mais formação e não apenas informação. (LAUDARES; MIRANDA, 2007, p. 4)

Os dados utilizados na pesquisa foram obtidos por meio de vários procedimentos metodológicos, dentre os quais: observações, anotações, entrevistas, relatórios, gravações e atividades investigativas.

\section{Análise e discussão da pesquisa}

Os sujeitos que participaram deste estudo foram 20 alunos do sétimo ano da Educação Básica com idades variando entre 11 e 13 anos, sendo sete do gênero masculino e 13 do gênero feminino. No que dizem respeito às famílias desses alunos, seus pais têm idades entre 34 e 56 anos e a maioria possui nível superior. Sobre a socialização entre os elementos da turma, verificou-se que os meninos possuem uma maior integração, sendo inclu- 
sive mais extrovertidos e unidos. As meninas são mais introvertidas e tímidas, formando pequenos grupos.

Minimizando os efeitos dessas condutas, os alunos foram separados em 10 duplas por meio de um sorteio realizado na primeira aula. Para realização da análise, as duplas não foram identificadas, e sim nomeadas por letras maiúsculas do alfabeto, a saber, A, B, C, D, E, F, G, H, I e J.

Em relação à participação nas aulas investigativas, os alunos tinham um bom comportamento e assiduidade satisfatória. Verificouse também que cerca de $60 \%$ dos alunos, nos tempos livres, utilizavam o computador como principal atividade lúdica, acessando, principalmente, a internet. Cerca de $90 \%$ dos alunos possuem computador em casa e $55 \%$ o utilizam freqüentemente. A maioria considera importante a presença do computador na escola, pois é essencial às atividades de pesquisa escolar

Considerar o computador somente uma ferramenta para pesquisa demonstra uma visão reducionista do uso da informática no ensino, pois se limita a considerar o computador uma máquina de ensinar e o aluno um ser passivo, que recebe a instrução. Esse tipo de aprendizado, Papert (1985) nomeou de instrucionismo. Numa outra visão de utilização do computador, a construcionista, que é um dos princípios do SuperLogo, o computador deve ser uma máquina de pensar com, auxiliando no desenvolvimento dos processos mentais incentivando o aluno a construir sua própria aprendizagem.

Para Papert (1985), a presença do computador contribui para os processos mentais não somente como um instrumento, mas essencialmente, de maneira conceitual, influenciando o pensamento das pessoas. Como o computador está presente no cotidiano dos alunos, houve grande facilidade da turma ao interagir com o SuperLogo, o que facilitou a realização deste trabalho.

Outra questão abordada nos questionários foi a relação do aluno com a matemática, Segundo Chacon (2000), os alunos que têm crenças rígidas e negativas acerca da Matemática e da sua aprendizagem, normalmente são aprendizes passivos e, no momento da aprendizagem, dão mais ênfase à memorização do que à compreensão. Pode-se verificar que cerca de $90 \%$ dos alunos gostam de matemá- tica e se consideram entre excelentes e bons na disciplina. Uma parte significativa da turma $(85 \%)$ acha que a matemática serve para fazer cálculos e resolver problemas. Somente $5 \%$ dos envolvidos concordam que a matemática exercita o cérebro e $10 \%$ afirmam que ela é útil ao dia a dia. Os alunos que não gostam da disciplina alegam que possuem notas baixas e consideram a disciplina muito difícil. A visão desses alunos é de que a matemática serve somente para fazer cálculos. Entre os que gostam da disciplina, $28 \%$ consideram-se alunos regulares, $22 \%$ consideram-se excelentes e $50 \%$ consideram-se bons em matemática. Todos os alunos regulares alegam dificuldades, e ainda afirmam que a matemática serve somente para realizar cálculos.

Outro fator interessante foi perceber que a uma significativa parte dos alunos gostam de Geometria, cerca de $40 \%$. Isso é facilmente justificado, pois a instituição implantou no ano anterior a esta investigação, uma aula semanal de Geometria na grade curricular. Também fizeram parte desta investigação os docentes da instituição, respondendo o questionáriodiagnóstico. No total a escola possui cinco professores de Matemática, dos quais $80 \%$ graduados em matemática e $20 \%$ formados em Contabilidade, com complementação pedagógica em Matemática. Somente $40 \%$ dos professores possuem pós-graduação. Sobre os aspectos pedagógicos, em específico a geometria, todos os professores afirmaram que conceitos geométricos são essenciais para o desenvolvimento da percepção do aluno. Sobre os aspectos tecnológicos, todos os professores possuem computador e acesso à internet domiciliar. A maioria utiliza esse recurso em sala de aula somente quando indicado pelo livro didático. Apenas um docente afirmou que utiliza a informática cotidianamente em suas aulas, conforme verificado com a coordenadora do laboratório de informática. Para esses educadores, os recursos tecnológicos, quando trabalhados de forma significativa, desenvolvem várias competências, dentre elas: percepção, aprendizagem, ludicidade e memorização.

\subsection{Contribuições do SuperLogo ao ensino de geometria}

Harold Abelson e Andrea diSessa no livro Turtle Geometry: The Computer as a Mediun 
for Exploring Mathematics (1981) afirmam que a coisa mais importante para lembrar-se da Geometria da Tartaruga é que ela é uma Matemática arquitetada para propiciar um aprendizado inicial por tentativas e exploração desde o primeiro momento.

Pode-se então dizer que a Geometria da Tartaruga apresenta um estilo diferente de abordar os mais diversos conteúdos da Geometria Euclidiana, Geometria Analítica, e das demais geometrias. Nela está presente o estilo axiomático-lógico de Euclides e o analítico de Descartes. Esses estilos estão inseridos no SuperLogo e presentes no micro mundo da tartaruga.

Cabe destacar que, além dos aspectos relacionados a vários tipos de geometria, o SuperLogo possibilita também o trabalho com outras áreas da disciplina, como: operações matemáticas básicas, transformações de medidas, fórmulas, resolução de problemas e a busca por estratégias.

O SuperLogo desenvolve também habilidades intelectuais e corporais, ajudando no desenvolvimento da localização espacial e do raciocínio lógico. Isto é perceptível quando o aluno executa alguns comandos básicos. Ele tem que se imaginar na posição da tartaruga e ao mesmo tempo, descobrir quais comandos deve executar. Esta habilidade é denominada de "[...] sintonicade cultural, na qual a Tartaruga liga a idéia de ângulo à navegação. Atividade positiva e firmemente enraizada à cultura extracurricular de muitas crianças." (PAPERT, 1985, p. 87)

Uma das formas geométricas mais abordadas no trabalho com o SuperLogo são os polígonos, principalmente os regulares. $\mathrm{Na}$ construção dessas figuras, os sujeitos devem constatar que o SuperLogo utiliza o ângulo externo para traçá-las. Constatam também os conceitos de ângulos suplementares e ainda verificam que, à proporção que o número de lados do polígono aumenta seu perímetro e sua área também aumentam e o polígono vai se aproximando da forma circular. Essa elaboração pode ser caracterizada como jogo de exercício, em que

[...] a forma de assimilação é funcional ou repetitiva, caracterizada pelo prazer da função, fazendo com que o sujeito realize as atividades com prazer, uma vez que fazem parte desse processo que, de forma gradativa, repete-se, numa aprendizagem que terá um fim em si mesma. (SILVA, 2003, p. 119)
Nesse processo de construção de polígonos regulares, os alunos utilizam seus esquemas de ação, aplicando os conceitos geométricos existentes na sua estrutura cognitiva (ângulos internos, externos e suplementares, soma dos ângulos internos e externos, área e perímetro) para a obtenção da figura desejada.

Se na execução de uma atividade com o SuperLogo, a resposta não é fornecida, o sujeito reflete sobre os erros apresentados analisando todas as etapas desde o início, num processo de compreensão e depuração. A maneira como ele vê o erro nessa perspectiva de trabalho proporciona uma melhor compreensão da situação e dos conceitos envolvidos, identifica o seu estilo de pensar e de relacionar-se com o mundo, ou seja, esse processo proporciona a produção do conhecimento.

A atividade LOGO torna explícito o processo de aprender de modo que é possível refletir sobre o mesmo a fim de compreendê-lo e depurá-lo. Tanto a representação da solução do problema quanto a sua depuração são muito difíceis de serem conseguidos através dos meios tradicionais de ensino e, portanto, estão omitidos do processo de ensino. (VALENTE, 1993, p. 16)

O SuperLogo possui ainda um excelente recurso para desenvolver o raciocínio lógico do aluno, ou seja a possibilidade das atividades produzidas, serem desenvolvidas por meio de uma linguagem de programação. Nas tarefas desenvolvidas, os alunos foram motivados a programar as atividades. Durante a programação do computador, os alunos da pesquisa construíram um diálogo com a máquina, no qual o educando digita um comando e o computador fornece um feedback. Com base nesse retorno é que o usuário oferece um novo comando ou reformula o comando anterior. Nesse processo, aprende-se a programar as tarefas e a conceituar os problemas pelo programa do computador.

\subsection{0 ambiente desenvolvido com a pesquisa}

O ambiente de trabalho criado pelo SuperLogo proporcionou aos alunos muita motivação, para desenvolverem seu potencial matemático. Como conseqüência deste ambiente instituído no estudo, destacam-se atitudes e reações positivas, que possuem como fundamentações básicas as idéias propostas por 
Piaget (1975) e outros teóricos. Esses fatos foram perceptíveis nas produções de textos sugeridas na pesquisa, nos diálogos gravados, nas respostas dadas aos questionários e nas observações feitas pelo pesquisador.

As interações realizadas com o auxílio do computador e em ambientes colaborativos de aprendizagem, como o SuperLogo, reforçam a idéia de que o conhecimento se constrói de forma compartilhada e que isto tem forte efeito motivador nos alunos. Essas interações nem sempre são livres de conflitos, principalmente quando há crianças atuando juntas. Cabe salientar que como os alunos investigados encontram-se no final do estágio operatório-concreto e início do operacional-formal, suas idéias e opiniões tendem a ser discutidas e refletidas, quando atuando em grupos socializáveis.

A metodologia utilizada nas atividades constituiu uma fonte de situações ricas em estímulos e fortemente lúdicas, podendo favorecer o desenvolvimento de aprendizagens significativas e sociais nos alunos. O trabalho em grupo favorece a troca de experiências, pois os diversos pontos de vista são apresentados criando um ambiente em que se configuram os jogos de regras.

Os jogos de regras são classificados como sendo aqueles que trabalham combinação sensóriomotora ou intelectual com competição de indivíduos e regulamentados quer por um código transmitido por geração a geração e por acordos momentâneos. (PIAGET, 1975, p. 184)

Foi necessária a realização de certas negociações na resolução das tarefas, pois as duplas estavam usando um único computador, desenvolvendo assim a noção de regras de trabalho em grupo e cooperativo, evoluindo em um estágio de jogos simbólicos e/ou jogos de exercício para jogos de regras.

A disputa e o jogo, aspectos existentes durante a realização deste trabalho, incentivaram os sujeitos a desenvolverem um trabalho colaborativo. Isto ficou evidenciado no momento em que uma dupla tentava terminar uma tarefa antes da outra, para mostrar sua solução aos colegas e poder opinar no trabaIho do outro. Esse intercâmbio não foi imposto pelo investigador participante, desenvolveu-se como uma norma social, já estabelecida pelos alunos, sem fazer necessária uma discussão ou normatização desta interação.

\subsection{Características do professor no ambiente SuperLogo}

O uso do SuperLogo requer um novo desempenho para o docente, no qual ele é mediador do processo ensino-aprendizagem. Como afirma Valente (1993) o novo papel do professor neste processo é o de facilitador, de mediador da aprendizagem, cujo centro é o aluno e não mais o currículo ou a maneira como o professor transmite o conhecimento.

O professor na perspectiva mediadora é aquele que usa métodos de intervenção diferenciados, em que o aluno utiliza seus erros e acertos num processo de descoberta e construção do conhecimento. Nessa visão, o professor deve possuir um papel de mediador da aprendizagem tendo características e funções bem estabelecidas, como destacadas abaixo:

a) O professor precisa ter o conhecimento do problema e do projeto proposto;

b) Deve conhecer os alunos e suas capacidades de interação, adaptando o problema proposto;

c) Incentivar a descrição da solução do problema;

d) Incentivar os diferentes níveis de reflexão (empírica e a pseudo-empírica e reflexiva). Assim, quando o aluno é questionado sobre a solução encontrada, este se vê estimulado a refletir, analisar e sintetizar suas idéias;

e) Proporcionar uma maior depuração permitindo ao aluno reestruturar suas idéias, seus esquemas e aplicá-los às atividades propostas;

f) Incentivar as relações pessoais, ou seja, socializações onde o grupo de colegas será visto como fonte de conhecimento assumindo de certa forma o papel do professor;

g) Este trabalho centrado numa nova idéia da prática docente requer trocas de paradigmas pedagógicos, pois o professor além de conhecer os conceitos pedagógicos que envolvem o construcionismo e o ambiente SuperLogo, deve também ser um aprendiz, servindo de modelo para o aluno.

Essas funções de professor mediador são logo percebidas pelo aluno. O professor passa a ser considerado um parceiro, cuja autoridade reside em seu nível mais abrangente de conhecimento, maturidade e experiência, 
mas que atua no processo de ensino-aprendizagem. O professor participa das discussões e emite opiniões, que podem ser questionadas e analisadas, em evidente contraste com a tradicional situação de sala de aula, em que o professor se coloca como o único detentor do saber e do conhecimento. Isto favorece a formação de um trabalho de cooperação e motivação na resolução das atividades propostas.

\section{Considerações finais}

Torna-se oportuno registrar que a utilização do Programa Computacional SuperLogo no desenvolvimento de conceitos geométricos tem sido relatada por várias pesquisas educacionais, entre as quais destacam-se: Os trabalhos realizados pelos portugueses Matos (1991), Bento (2002), Ponte e Serrazina (2000), Correia (2005) e Gravina e Santarosa (1998), que caracterizam a Linguagem SuperLogo como sendo um programa educativo de excelência, para abordar atividades geométricas investigativas, bem como idéias e conceitos matemáticos. As pesquisas de Mestrado (1994) e Doutorado (1999) de Rosana Miskulin que visam a identificar as concepções teórico-metodológicas sobre a utilização de computadores no processo ensino/aprendizagem da geometria. Outra pesquisa que mereceu destaque foi o trabalho desenvolvido na Universidade de Londres, por Richard Noss e Celia Hoyles (1992). Publicaram o livro Learning Mathematics and Logo, que apresentava uma coletânea de artigos que relacionam o SuperLogo à Educação Matemática.

As publicações de José Armando Valente, pesquisador e docente da Unicamp, que publicou vários livros e textos, com temáticas relacionadas ao emprego da informática na educação e o uso do SuperLogo no ensino. Dentre suas obras destacam-se: Computadores e Conhecimento: repensando a educação (1996), Formação de Educadores Para o Uso da Informática na Escola (2003), O Computador na Sociedade do Conhecimento (1999), O Professor no Ambiente Logo: Formação e Atuação (1999) e Diferentes usos do Computador na Educação (1995).

O objetivo da presente pesquisa foi o de investigar de que forma o uso do SuperLogo nas aulas de matemática contribui para o de- senvolvimentos dos conceitos geométricos. Em conseqüência, outra preocupação foi observar o ambiente criado com a utilização do software, verificando os aspectos atitudinais criados a partir da interação dos alunos com o SuperLogo. Assim, o volume de pesquisas e trabalhos registrados, nos últimos anos, justificam a importância dada ao SuperLogo neste trabalho e o objetivo proposto, pois evidenciam as implicações da utilização do programa no desenvolvimento cognitivo dos alunos, em específico no aprimoramento dos conceitos geométricos.

Apesar de todas as potencialidades apresentadas pelo SuperLogo, algumas dificuldades técnicas e pedagógicas do software são destacadas.

Sobre as dificuldades técnicas, destacamse: O programa não tem plugin que permita a publicação de projetos em páginas da internet. Dessa forma, atividades realizadas não podem ser apresentadas em formato html, o que dificulta a divulgação dos projetos desenvolvidos pelas escolas. Os projetos realizados somente são armazenados na forma de procedimentos, ou seja, os comandos necessários, não a figura obtida, e toda vez que esses arquivos são utilizados faz-se necessário utilizar procedimentos. Só é possível rodar o SuperLogo em Linux se estiver instalado um emulador que faz com o programa não fique lento.O SuperLogo não possui uma interface e interatividade gráfica que agrada aos alunos.

Em relação às dificuldades pedagógicas, destacam-se: Atualmente, alguns professores, principalmente das séries iniciais da Educação Básica, sentem dificuldade em trabalhar com o SuperLogo, pois a linguagem possui implícito um conhecimento matemático e um raciocínio lógico prévio por parte do educador. Alguns professores, ao trabalharem com o SuperLogo, afirmam que os alunos sentem-se cansados em interagir com o software e solicitam outro tipo de atividade. Esse cansaço deve-se provavelmente ao fato de se proporem atividades em que os alunos somente aplicam os comandos do programa, não interagindo entre si e nem desenvolvendo suas habilidades intelectuais. Alguns teóricos criticam o fato do SuperLogo desenvolver, desde as séries iniciais, uma linguagem de programação. Resnick (1993) compara essa afirmativa com a do tempo em que se pensava que nem todos precisavam aprender a 
ler e a escrever. Hoje, há os que defendem a posição de que os conceitos e generalizações de uma programação não devem ser ensinados a todos. No entanto, a experiência em programação é útil ao desenvolvimento do raciocínio lógico, pois o ato de programar exige sucessivas antecipações e projeções sobre os resultados das várias partes de um objeto simbólico.

Apesar das dificuldades, vale ressaltar que não basta apenas repensar a aprendizagem e a informática. Faz-se necessário que se busque o conhecimento sobre o que se pretende no ato de ensinar, explicitando objetivos claros e não somente trabalhando o software pelo software.

Para Petry (1996) ao utilizar qualquer um software, o professor deve ser visto como alguém que aprende, e não deve tentar impor sua opinião e metodologia, mas tomar qualquer experiência com computadores em educação como fonte de discussão e reflexão sobre a aprendizagem.

O contato do aluno com o SuperLogo contribuiu para o desenvolvimento de conceitos geométricos, por meio de uma matemática própria, presente no ambiente de aprendizagem interagindo com a geometria da tartaruga.

Tal interação desenvolveu um modelo de pensamento reflexivo, no qual o conhecimento é obtido por meio de manipulações do próprio aluno, ou seja, em um processo de construção da aprendizagem.

Sendo assim, o Programa Computacional
SuperLogo possibilitou a compreensão de determinados conhecimentos geométricos, ampliando-se a capacidade do aluno de lidar de forma significativa e inteligível com diversos conteúdos matemáticos.

Alcançou-se, segundo nossas observações, um objetivo maior, subjacente ao ensino da matemática, que foi o de preparar as mentes de nossos estudantes para um contato com uma matemática mais investigativa e de caráter construtivo. Conseqüentemente, essa matemática, pelo fato de ser interrogada continuamente no seu fazer, caminha em direção a sistematizações, formalizações, provas e demonstrações.

Em resumo, pode-se afirmar que nos depoimentos de alunos e professores, nas evidências, nas análises e no ambiente criado, o objetivo geral deste trabalho se concretizou. Mais do que verificar de que forma o uso adequado do SuperLogo poderia contribuir para o desenvolvimento de conceitos geométricos, vivenciou-se durante a pesquisa um ambiente de ensino, aprendizagem, educação e cidadania, pois o software possibilita a interação e a troca de experiência entre todos os envolvidos no processo (alunos $x$ aluno, aluno $x$ professor e professor $x$ aluno). Sentiu-se, ao longo do processo, que o próprio estudante começou a perceber, ainda que de forma implícita, que um software deve ser visto em sua dimensão de instrumento facilitador e que o importante é o processo de construção do conhecimento matemático e do espaço educacional.

\section{Referências}

ABELSON, H.; DISESSA, A. Turtle Geometry. 1981.

BORBA, M.C.; PENTEAdo, M.G. Informática e Educação Matemática. Belo Horizonte: Autêntica Ed., 2001.

BRASIL. Ministério da Educação e do Desporto. Secretaria de Educação Fundamental. Parâmetros Curriculares Nacionais: Terceiro e Quarto Ciclos do Ensino Fundamental: Matemática. Brasília, 2001.

CORREIA, L.H.A.; AMARAL, K.C.A.; UCHOA, J.Q. Computador Tutelado. Lavras: UFLA/FAEPE, 2001.

COSTA, J.W.; OLIVEIRA, M.A.M. (Org.). Novas Linguagens e Novas Tecnologias. Petrópolis: Ed. Vozes, 2004.

FERRUZZI, E.C. Considerações Sobre a Linguagem de Programação Logo. Florianópolis: UFSC/Grupo de Estudo de Inteligência Artificial Aplicada à Matemática, 2001.

LUDKE, M.; ANDRÉ, M.E.D.A, Pesquisa em Educação: abordagens qualitativas. São Paulo: EPU, 1986. 
MAGGI, L. A Utilização do Computador e do Programa Logo Como Ferramenta de Ensino de Conceitos de Geometria Plana. 2002. Dissertação (Mestrado em Educação Matemática) - Instituto de Geociências e Ciências Exatas, 2002, Rio Claro, BR-SP.

MATOS, J.F. Logo na Educação Matemática: um estudo sobre as concepções e atitudes dos alunos. Lisboa: APM, 1991.

MIRANDA, D.F.; LAUDARES, J.B. Informatização no Ensino de Matemática: investindo no ambiente de aprendizagem. Zetetiké, São Paulo, v. 15, n. 27, p. 71-88, jan./jun. 2007.

MISKULIN, R.G.S. Concepções Teórico-Metodológico Baseadas em Logo em Resolução de Problemas Para o Processo de Ensino/Aprendizagem da Geometria. 1994. Dissertação (Mestrado em Educação) - Faculdade de Educação, Universidade Estadual de Campinas, 1994, Campinas, BR-SP.

MOTTA, M.S. Contribuições do SuperLogo ao Ensino de Geometria do Sétimo Ano da Educação Básica. 2008. Dissertação (Mestrado em Ensino de Ciências e Matemática) - Pontifícia Universidade Católica de Minas Gerais, 2008, Belo Horizonte, BR-MG.

PAPERT, S. Logo: computadores e educação. São Paulo: Brasiliense, 1985.

PAPERT, S. A Máquina das Crianças: repensando a escola na era da informática. Porto Alegre, Artes Médicas, 1994.

PETRY, P.P. Por que Odeiam a Tartaruga? Projeto Educadi. Porto Alegre: UFRGS, 1996. Disponível em: <http://lec.psico.ufrgs.br/ pppetry/logo1.html> Acesso em: 18 set. 2007.

PIAGET, J. A Equilibração das Estruturas Cognitivas. Rio de Janeiro: Zahar, 1975.

PONTE, J.P.; CANAVARRO, A.P. Matemática e Novas Tecnologias. Lisboa: Universidade Aberta, 1997.

RESNICK, M. Future visions of programming in education. In: ESTES, N.M.; SILVA, C.M. Uso do Logo na Sala de Aula, Desempenho em Geometria e Atitudes em Relação à Matemática. 2003. Dissertação (Mestrado em Educação) - Universidade Estadual de Campinas, 2003, São Paulo, BR-SP.

VALENTE, J.A. Computadores e Conhecimento: repensando a educação. Campinas: Graf. da UNICAMP, 1993.

VALENTE, J.A. O Professor no Ambiente Logo: formação e atuação. Campinas: Graf. da UNICAMP, 1999a.

VALENTE, J.A.; ALMEIDA, F.J. Visão Analítica da Informática na Educação: a questão da formação do professor. Revista Brasileira de Informática na Educação, Florianópolis, n. 1, p. 45-60, 1997.

Recebido em julho de 2009.

Aprovado para publicação em agosto de 2009.

\section{Marcelo Souza Motta}

Doutorando em Ensino de Ciências e Matemática da Universidade Cruzeiro do Sul e professor Assistente da Universidade Federal do Mato Grosso do Sul - UFMS - Campo Grande - MS/Brasil

Email: msmotta27@gmail.com

\section{Ismar Frango Silveira}

Doutor em Engenharia Elétrica. Docente da Universidade Cruzeiro do Sul- UNICSUL - São Paulo-SP/Brasil. Pesquisador em Adaptatividade de Objetos de Aprendizagem.

Email: ismar.silveira@cruzeirodosul.edu.br 


\section{ANEXOS}

\section{a) Atividades Investigativas}

\section{Atividade 01 - Poliminós}

Os poliminós são peças formadas pela junção de quadrados. Podem-se dividir os poliminós em famílias. Os grupos mais utilizados são: dominós, triminós, quadriminós, pentaminós e hexaminós. Observe os exemplos:

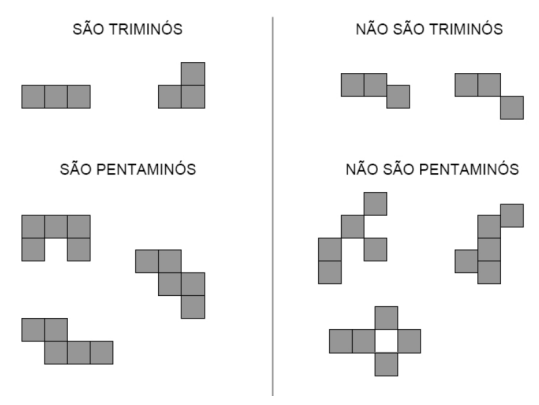

Nesta atividade, trabalharemos somente com os hexaminós. Descubra e desenhem alguns deles. Observando os hexaminós, verifique quais formam as planificações de um cubo, crie e execute um procedimento para desenhar três dessas planificações.

Quantas planificações do cubo vocês encontraram?

Escreva um relatório sobre a execução desta tarefa, registrando todas as etapas realizadas.

\section{Atividade 02 - Cara}

Crie e execute um procedimento que desenhe uma "cara". A cara deve ter duas orelhas, dois olhos, nariz e boca.

- a cara deve ser constituída de retângulos, quadrados, triângulos e círculos;

- deve conter pelo menos um retângulo, um quadrado e um triângulo;

- deve ser colorida;

- pode ser redonda;

- o perímetro de cada uma das partes da cara deve ser:

\begin{tabular}{|c|c|}
\hline Parte da Cara & Perímetro \\
\hline Nariz & 90 \\
\hline Boca & 160 \\
\hline Olhos & 100 cada \\
\hline Orelhas & 120 cada \\
\hline
\end{tabular}

Escreva um relatório sobre a execução desta tarefa, registrando todas as etapas realizadas.

\section{Atividade 03 - Caixa}

Material: Caixa de remédio vazia.

Observe a caixa trazida para a aula e resolva o que se pede:

a) Faça um esboço dessa caixa, destacando as medidas de suas arestas;

b) Complete a tabela:

\begin{tabular}{|c|c|}
\hline $\begin{array}{c}\text { Dimensóes da } \\
\text { Caixa } \\
(\mathrm{cm})\end{array}$ & $\begin{array}{c}\text { Equivalente } \\
\text { a passos de } \\
\text { tartaruga }\end{array}$ \\
\hline & \\
\hline & \\
\hline & \\
\hline
\end{tabular}

c) Qual o volume dessa caixa

- em centímetro?

- em passos de tartaruga?

d) Faça um esboço da planificação dessa caixa.

e) Crie e execute um procedimento para desenhar a planificação dessa caixa.

f) Escreva um relatório sobre a execução desta tarefa, registrando todas as etapas realizadas. 


\section{Tarefa 04 - Bandeira do Brasil}

Desenhe e pinte a Bandeira do Brasil em seu caderno, e depois faça o que se pede:

a) Quais as formas geométricas que compõem a bandeira do Brasil?

b) Qual o valor dos ângulos internos de cada uma dessas figuras?

c) Crie e execute um procedimento que desenhe a bandeira do Brasil, considerando as observações abaixo:

- todas as cores devem ser respeitadas;

- não é necessário desenhar a faixa branca e nem escrever "Ordem e Progresso";

- as medidas podem ser escolhidas pela dupla, desde que proporcionais ao modelo original;

d) Escreva um relatório sobre a execução desta tarefa, registrando todas as etapas realizadas.

\section{Tarefa 05 - Relatório Final}

Elabore um relatório abordando os seguintes tópicos:

- a importância do trabalho com o SuperLogo;

- o que o uso do logo auxiliou em sua aprendizagem de Geometria e Matemática;

- os conteúdos aprendidos ou ressignificados;

- a importância do uso do computador na aula;

- $\quad$ se gostou ou não da realização desta atividade;

- $\quad$ principais conclusões da atividade.

b) Projeto Igreja

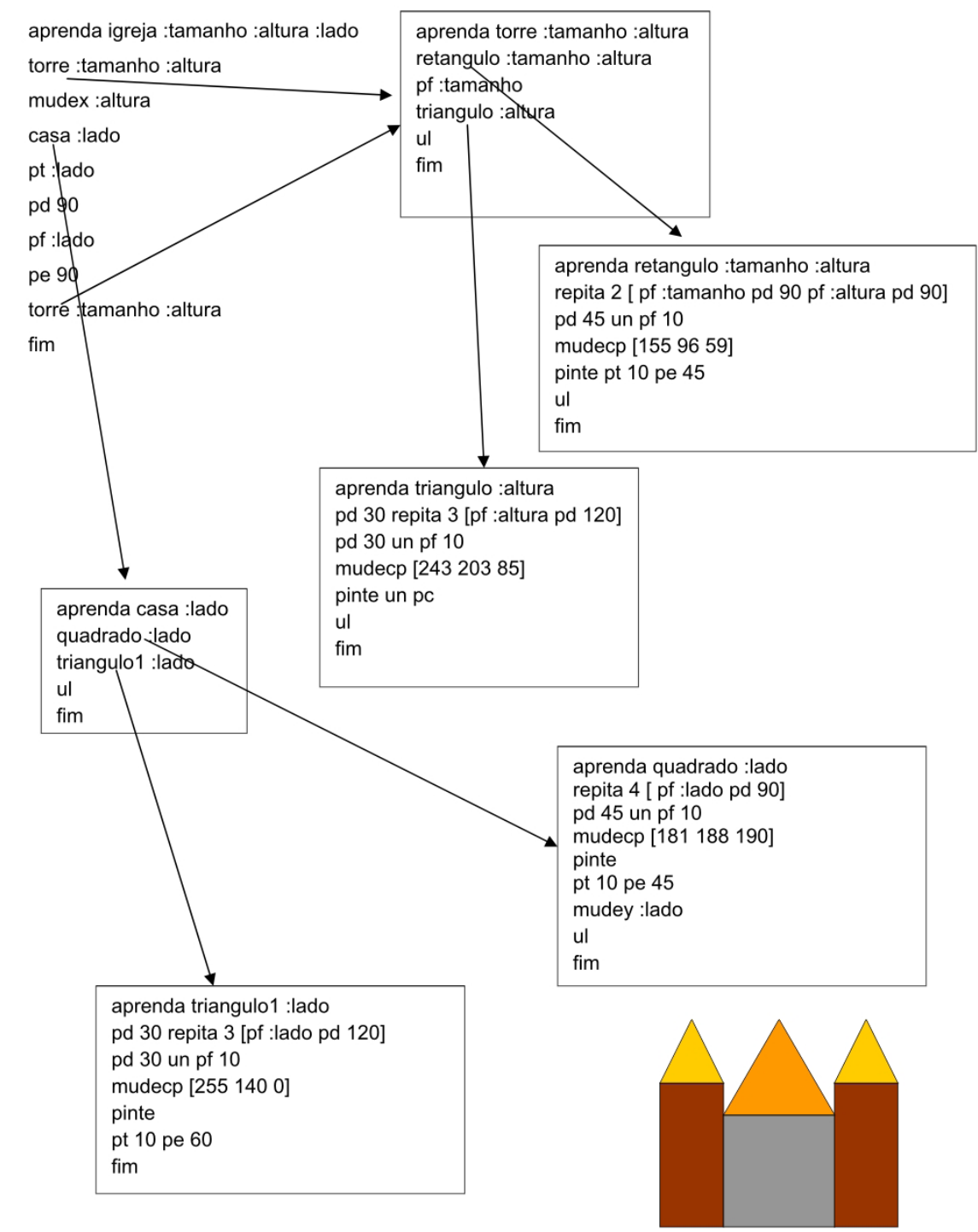

